\title{
AC 2012-3460: A PHYSICAL MODEL FOR THE DOT PRODUCT: DOES IT IMPROVE LEARNING OF VECTOR MECHANICS?
}

\section{Luciano Fleischfresser, Universidade Tecnolgica Federal do Paran}

Luciano Fleischfresser is an Associate Professor at Universidade Tecnolgica Federal do Paran, where he teaches the vector mechanics sequence (statics and dynamics) for engineering majors. Fleischfresser holds a Ph.D. from the University of Oklahoma's School of Meteorology and bachelor's/master's degrees in mechanical engineering from Universidade Federal do Paran and Universidade Federal do Santa Catarina respectively. His research interests are in engineering educational research and in environmental fluid mechanics.

\section{Mariana Nascimento Casarin, Universidade Tecnolgica Federal do Paran}

Mariana Nascimento Casarin was born in Campo Mouro, Paran. She graduated with honors from the high school computer technical program offered at Universidade Tecnolgica Federal do Paran, Campo Mouro xampus (UTFPR CM), in 2011. She is now enrolled as a freshman in the electronic engineering program at the same institution.

\section{Evandro Eizo Roncaglia Yabushita, Universidade Tecnolgica Federal do Paran}

Evandro Eizo Roncaglia Yabushita was born in Maring, PR, and he lived in the town of Santa F until he was 18 years old. He was admitted to Universidade Tecnolgica Federal do Paran, Campo Mouro campus (UTFPR-CM), in 2008. Currently, Roncaglia Yabushita is a junior in the environmental engineering program. 


\section{A physical model for the dot product:}

\section{Does it improve learning of Vector Mechanics?}

\section{Introduction}

By the end of the $20^{\text {th }}$ century, it became widely recognized that a paradigm shift in engineering education would have to be made ${ }^{1}$. Active learning, problem-based learning, peer collaboration and other approaches have been emphasized due to their inherent appeal to the diversity of learning styles ${ }^{2}$ in today's classrooms. The temptation to teach as others have taught us is great, and preparing lecture notes to deliver on the chalkboard is natural in a room designed for traditional lecturing. But routine practice leads to boredom, so we soon find ourselves digging for better ways of doing things. The quest is not hard as one can easily stumble upon writings that inform us how to become better teachers ${ }^{3,4}$.

A hybrid approach for teaching statics is a promising way to improve learning of engineering sophomore students ${ }^{5,6}$. Teaching a generation growing in the information age (the net generation) presents a challenge that we still do not fully understand. Nathan reports on the use of multimedia tools as a way to connect with students and enhance their learning experience ${ }^{7}$ whereas Dollár and Steif focus on building objects to explore concepts of a learning module ${ }^{8}$. Soler and Rabelo offer an intriguing demonstration to excite students on the concept of equilibrium ${ }^{9}$. While we generally accept such approaches as better than traditional lecturing, attempts to quantify better learning -- as opposed to qualify it -- are not clear cut. Some studies rely solely on statistical analyses while others are based on pre- and post-tests, and there are other approaches. Lack of an established methodology seems to be a problem in engineering education research. There is recent evidence of problem-solving skill improvement of 2-D situations using paper and pencil solutions, video recordings, and statistical analyses ${ }^{10}$. Such studies depend on the availability of representative samples and are not always straightforward to accomplish.

Engineering mechanics (statics and dynamics) classes are usually required from all engineering majors in universities around the world. They are the first encounters a student has with the engineering method of solving problems. An important skill to be a successful statics problem-solver is spatial visualization. Sorby and Baartmans have established that male students are ahead of their female counterparts on this skill ${ }^{11}$. They have shown that introductory spatial visualization classes help reduce this gender gap. On the other hand, Shryock et. al. have provided calculus and physics mechanics skills needed to be successful in sophomore statics and dynamics courses ${ }^{12}$. Here there is apparently no gender preference. Lesko et. al. have explored the use of physical models of trusses, beams, and structures in general to help solving statics problems ${ }^{13}$, but, to our knowledge, none has explored a fundamental concept like the dot product, and related it to a concrete experience. It turns out that the dot product is an important vector algebra property that many people take for granted as a purely mathematical concept. Our hope is that relating its calculation with an actual measurement of its result provides confidence and awe on its applicability. 
The rest of the paper presents the original problem that motivated our investigation and the analysis performed last semester. After introducing the physical model, the way it was used to energize learning is presented. We discuss how errors made by students on test day can be related to gender and to being in class when the model was shown.

\section{Method}

Shames provides the motivation for the physical model ${ }^{14}$. Its vector algebra chapter presents a mature treatment emphasizing 3-D vector representations. Figure 1 is from the original problem. It asks one to calculate the projection of the $500 \mathrm{~N}$ force along the diagonal from $\mathrm{B}$ to A. As emphasized by Roberts, the two important quantities that students must become familiar with in an introductory statics course are distance (length) and force ${ }^{15}$. There is no difficulty in visualizing length as a position or a displacement vector. However, a force vector is more difficult to visualize. We can feel the effect of its application, but we can rarely see the force itself. Since our intent is to offer a tangible application for the scalar product, we modified the original problem to calculate the projection of a position vector instead.

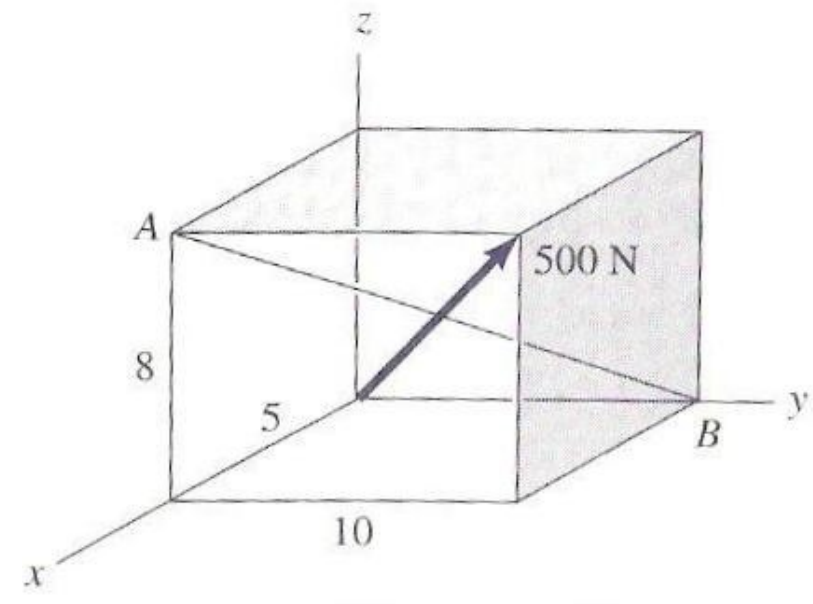

Figure 1: The textbook figure of the original problem $^{14}$.

The new problem illustration is shown on figure 2 along with the physical model built. The problem now becomes one of determining the rectangular component of the position vector $\vec{r}$ along the direction of the displacement vector $\vec{d}$. This component is the black portion of the diagonal painted on the white string. Note the fishing lines coming out of the start and of the end of the yellow vector. They attach to the white thick string making a $90^{\circ}$ angle with it. Measuring the length of the black portion gives the numerical value of $\vec{r} \cdot \hat{d}$ ( $\hat{d}$ being a unit vector). It provides a compelling visual evidence for the dot product concept. 


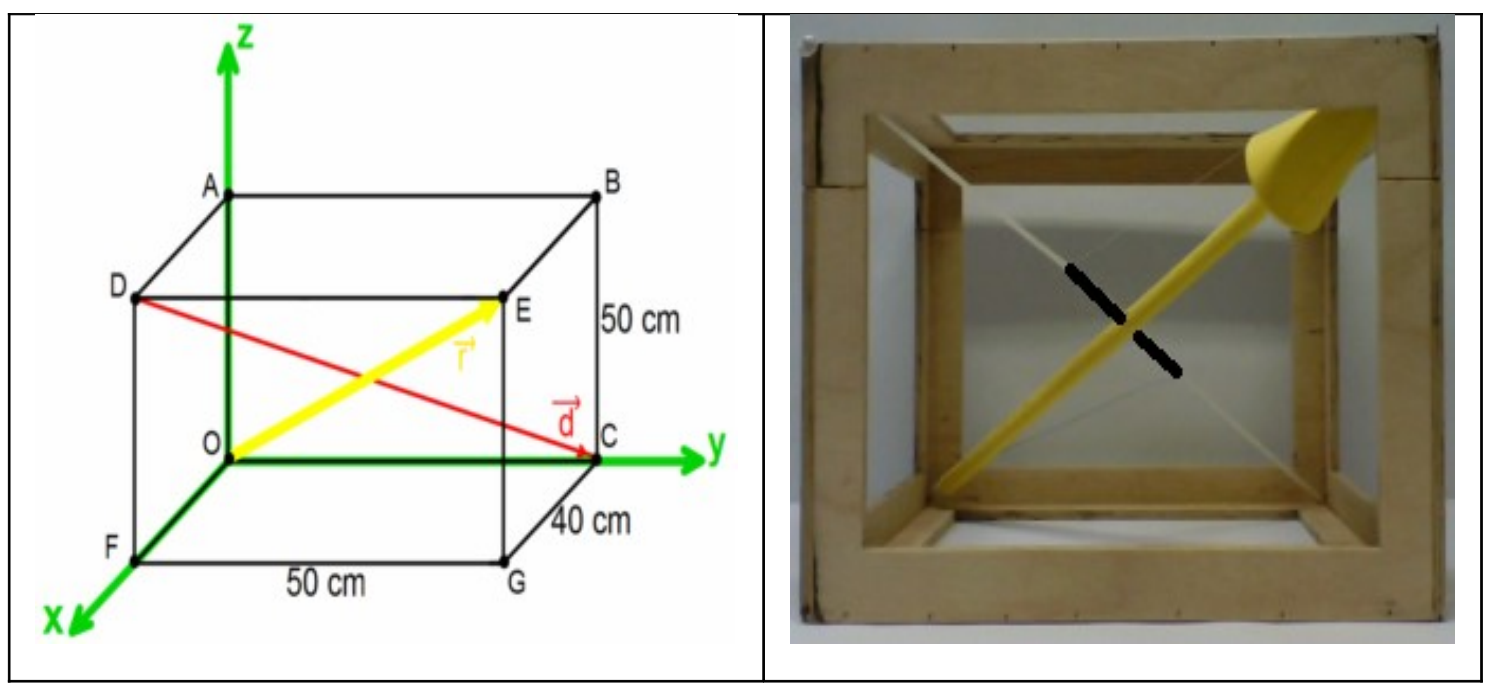

(a)

(b)

Figure 2: (a) The modified figure and (b) the physical model ${ }^{16}$

Generally, the solution to this problem requires four steps. First, students need to recognize the use of the dot product to find the projection of $\vec{r}$ on $\vec{d}$. Then they need to conceptualize how to perform the scalar product, that is, obtain $\hat{d}$, express $\vec{r}$ in terms of $\hat{\imath}, \hat{\jmath}$ and $\hat{k}$, and finally operate the scalar product. In effect:

$$
\begin{gathered}
\vec{r}=40 \hat{\imath}+50 \hat{\jmath}+50 \hat{k}(\mathrm{~cm}) ; \quad \hat{d}=-0.4924 \hat{\imath}+0.6155 \hat{\jmath}-0.6155 \hat{k} \text { (no units) } \\
\vec{r} \cdot \hat{d}=-19.69+30.78-30.78=-19.69(\mathrm{~cm})
\end{gathered}
$$

The minus sign serves to remind us that the scalar component of $\vec{r}$ along $\vec{d}$ is in the opposite direction of $\vec{d}$ itself.

We used this problem with a class size of 43. The problem's solution was highlighted on the chalkboard, time was given for students to copy it, and the prototype was brought to the front table and used to measure the $20 \mathrm{~cm}$ length of the black portion of the string. Two and a half weeks later, the same problem was given on the midterm exam with a slight modification: $\vec{d}$ was chosen along a different diagonal. Admittedly, this is not an easy problem. It requires high-level thinking skills and proficiency with vector operations. Both traits are acquired with time and practice.

\section{Assessment}

The grading revealed that only $42 \%$ of the class solved the problem correctly (18 students). The mistakes made by the rest of the class were put in four different categories: 1) show the result as a vector (19 students); 2) try to solve as learned in previous math class (2 students); 3 ) sign error that prevented reaching correct numerical value (2 students) and; 4) misconception on the problem ( 2 students). In what follows, we illustrate samples of student work in each of these categories. 
We show the breakdown between male and female students on table 1. This is according to how they did on the exam problem, and if they were in class or not when the topic was covered and the prototype was shown. Note that all the 11 students missing class made some type of error. The "GPA-equivalent" for each group is also shown. This is a performance index calculated for each student that takes into account all grades received up to that point in their programs. This index also takes into account the roll calls for each class as an aggregate.

Table 1. Performance of students on test day. Values in red are for those missing class. Decimal numbers are the GPA-equivalents on a 0 to 1 scale. For the "No error" (Male and Female) and "Error 1" (only Male) types, average GPA-equivalents are given. Others are individual values.

\begin{tabular}{lll}
\hline & Male & Female \\
\hline No error & $9(0.66)$ & $9(0.66)$ \\
Error 1 & $\mathbf{8}+\mathbf{8}(0.51$ and 0.54$)$ & $\mathbf{2}+1(\mathbf{0 . 5 3}$ and $0.54 ; 0.67)$ \\
Error 2 & $\mathbf{2 ( 0 . 6 2}$ and $\mathbf{0 . 6 3 )}$ & $\mathbf{0}$ \\
Error 3 & $\mathbf{1}(\mathbf{0 . 5 6 )}$ & $\mathbf{1}(\mathbf{0 . 6 2 )}$ \\
Error 4 & $\mathbf{1}(0.55)$ & $\mathbf{1}(0.64)$ \\
Total & $\mathbf{2 9}$ & $\mathbf{1 4}$ \\
\hline
\end{tabular}

With error type 1, the problem was reporting the answer as a vector. Students expressed $\vec{r}$ and $\hat{d}$ correctly but on performing the dot product they kept a vector expression. In effect:

$$
\vec{r} \cdot \hat{d}=-19.69 \hat{\imath}+30.78 \hat{\jmath}-30.78 \hat{k}
$$

Error type 2 showed evidence of performing the dot product as typically learned in math classes. It was apparently a problem of lack of attention in converting units rather than with the way the calculation was performed.

$$
{ }_{\hat{d}} \operatorname{Proj} \vec{r}=\frac{(4,5,5)(-0.4924,0.6155,-0.6155)}{\left(0.4924^{2}+0.6155^{2}+0.6155^{2}\right)^{1 / 2}}=\frac{-1.96+3.08-3.08}{0.99}=1.98 \text { (no units) }
$$

Sign errors are common during timed exams and they do not necessarily reflect a conceptual problem if all else is in order. For error type 3 , a student had the unit vector $\hat{d}$ with sign errors that prevented reaching the final correct numerical answer. Or:

$$
\hat{d}=0.4924 \hat{\imath}+0.6155 \hat{\jmath}+0.6155 \hat{k}
$$

Which lead to,

$$
\vec{r} \cdot \hat{d}=19.69+30.78+30.78=81.25(\mathrm{~cm})
$$

Finally, only 2 students were classified as having error type 4. One student expressed the dot product as $\hat{r} \cdot \hat{d}$, or:

$\hat{r} \cdot \hat{d}=(0.4924 \hat{\imath}+0.6155 \hat{\jmath}+0.6155 \hat{k}) \cdot(-0.4924 \hat{\imath}+0.6155 \hat{\jmath}-0.6155 \hat{k})$ 
And the final result,

$$
\hat{r} \cdot \hat{d}=-0.2425 \text { (no units) }
$$

\section{Discussion}

Our study is limited in at least two fronts: 1) we have a small sample size (43 students) and; 2) our methodology is essentially observational (quasi-experiment ${ }^{17}$. Pillati et. al. emphasize the need to incorporate psychometric measures in educational research studies ${ }^{18}$. Lack of these measures may cast doubt on data reliability and internal consistency, as well as on the validity of the conclusions. However, we feel that a bigger sample size would be required to incorporate these measures in our analysis. While we bear these limitations in mind, some reflections on the assessment performed are given below.

As a group, female students gained more from the concrete experience than their male counterparts. Here, $64 \%$ of them solved the problem correctly compared with only $31 \%$ of males. This might suggest the physical model is helping these students improve their spatial visualization skills, which in turn help them become better engineering problem-solvers. The fact that 9 out of the 11 students missing class had error 1 on exam day is at least curious. These 11 students had an overall attendance of $74 \%$ until the end of November. Classes resumed on December 17 2011. The other 32 students in class had an overall attendance of $68 \%$ in the same period, and the class as a whole (43 students) had an average attendance of $69 \%$. Thus, the 11 missing students on that special day are not the ones with the worst attendance overall.

With regard to the GPA-equivalent index shown on table 1, note that the best indexes are related with the "No error" student category. Those solving the problem correctly are generally the ones sitting on the front rows, missing few classes during the semester, and with good historical grades. One might argue that these students would still solve the problem convincingly regardless the prototype was shown or not. Here we caution that they also had a better view of the model since most of them were sitting closer to the chalkboard.

\section{Summary and Conclusions}

We investigated the following question: Can spatial visualization and problem-solving skills be improved with the use of a 3-D physical model to illustrate the dot product of vectors? We built a prototype to illustrate the concept, brought it to class when the topic was presented, and then asked students to solve a similar problem on the mid-term exam. The performance on this particular problem was tabulated according to 4 error types revealed during grading. The result was then related to gender and to absent students on the day the prototype was shown.

The analyses revealed that 9 out of 14 females benefited from the demonstration as indicated by a correct solution on exam day. By the way of contrast, only 9 out of 29 males had a correct solution. This result suggests that the concrete experience of a physical model was more effective for the female students. Students missing class when the model was shown (9 
males and 2 females) had mistakes in their solutions. This fact lends support to the importance of being exposed to a concrete experience to improve learning of an abstract concept like the dot product of vectors.

\section{Acknowledgments}

We'd like to thank the anonymous reviewers for their useful criticisms. The original abstract and first drafts were greatly improved by their comments and suggestions.

This work would not be possible without the support of UTFPR with a teaching assistant position for Evandro Yabushita in 2010, and a research assistant position for Mariana Casarin during 2011. Evandro is an undergraduate student in the Environmental Engineering program at UTFPR Câmpus Campo Mourão. The financial support for Mariana was provided by Fundação Araucária under their research experience program for high school students.

\section{Bibliography}

1. National Academy of Engineering. Educating the Engineer of 2020 - Adapting Engineering Education to the New Century. 2005. The National Academies Press.

2. Coffield, Frank, Moseley, David, Hall, Elaine, and Ecclestone, Kathryn. Learning styles and pedagogy in post-16 learning - A systematic and critical review. Learning and Skills Research Centre, 2004.

3. Felder, Richard M., Woods, Donald R., Stice, James E., and Rugarcia, Armando. The Future of Engineering Education II. Teaching Methods That Work. Chemical Engineering Education, 34(1), 26-39, 2000.

4. Kipper, Hants, and Ruutmann, Tiia. Teaching Strategies for Direct and Indirect Instruction in Teaching Engineering. International Journal of Engineering Pedagogy - Volume 1, Issue 3, October 2011. Available at http://www.i-jep.org.

5. Peercy, Paul S. and Cramer, Steven M. Redefining Quality in Engineering Education through Hybrid Instruction. Guest Editorial. Journal of Engineering Education. October 2011, Vol. 100, No. 4, pp. 625-629. American Society for Engineering Education.

6. Rezaei, Amir G., Kim, Kyu-Jung, Mariappan, J., Shih, Angela C. Lessons Learned from a Newly Developed Hybrid Vector Statics Course Based on Fundamental Concepts and Hands on Experiments. Proceedings of the 2007 American Society for Engineering Education Pacific Southwest Annual Conference.

7. Nathan, Rungun. Integrating Multi-Media Aids (Tablet-PC, Streaming Videos, Electronic Slides) to the Fundamental Instruction in Mechanics. American Society for Engineering Education, 2006.

8. Dollár, Anna and Steif, Paul S. Learning Modules for Statics. International Journal of Engineering Education. Online Paper. 2006.

9. Soler, José Gabriel M., and Rabelo, Ana Paula B. Ensinando com "Mágica": Equilíbrio Estático. Revista de Ensino de Engenharia, v. 26, n. 1, p. 27-31, 2007. 
10. Taraban, Roman, Craig, Curtis, and Anderson, Edward E. Using Paper-and-Pencil Solutions to Assess Problem Solving Skill. Journal of Engineering Education, July 2011, Vol. 100, No. 3, pp. 498-519. American Society for Engineering Education.

11. Sorby, Sheryl A., and Baartmans, Beverly J. The Development and Assessment of a Course for Enhancing the 3-D Spatial Visualization Skills of First Year Engineering Students. Journal of Engineering Education. July 2000, pp. 301-307. American Society for Engineering Education.

12. Shryock, Kristi J., Srinivasa, Arun R., and Froyd, Jeffrey E. Developing Instruments to Assess First-year Calculus and Physics Mechanics Skills needed for a Sophomore Statics and Dynamics Course. $41^{\text {st }}$ ASEE/IEEE Frontiers in Education Conference. October 12-15, 2011, Rapid City, SD.

13. Lesko, J., Duke, Jack, Holzer, SSeigfried, and Auchey, F. Hands-on-Statics Integration into an Engineering Mechanics - Statics Course: Development and Scaling. Proceedings of the 1999 ASEE Annual Conference \& Exposition.

14. Shames, Irving H. Engineering Mechanics - Statics and Dynamics. Fourth Edition. Prentice-Hall 1997.

15. Roberts, A. P. Statics and Dynamics with Background Mathematics. Cambridge University Press, 2003.

16. Casarin, Mariana N., Fleischfresser, L., and Yabushita, Evandro E. R. Confecção de Maquetes para a Disciplina de Mecânica Geral I. XVI SICITE - Seminário de Iniciação Científica e Tecnológica da UTFPR. Ponta Grossa - PR, 2011.

17. Shavelson, Richard J. and Towne, Lisa. Scientific Research in Education. Center for Education. Division of Behavioral and Social Sciences and Education. National Research Council. 2003.

18. Pilatti, Luiz Alberto, Pedroso, Bruno, and Gutierrez, Gustavo Luis. Psychometric properties of measurement instruments: a necessary debate. Revista Brasileira de Ensino em Ciência e Tecnologia. Vol. 3, num. 1, 2010. pp. 81-91. 